\title{
PATHOGENICITY AND PATHOLOGY OF Streptococcus agalactiae IN CHALLENGED MOZAMBIQUE TILAPIA Oreochromis mossambicus (PETERS 1852) JUVENILES
}

\author{
Thangapalam Jawahar Abraham (D), Meshram Supradhnya Namdeo (D), Harresh Adikesavalu (D), \\ Sayani Banerjee (D)
}

Cite this article as:

Abraham, T.J., Namdeo, M.S., Adikesavalu, H., Banerjee, S. (2019). Pathogenicity and pathology of Straptococcus agalactiae in challenged Mozambique tilapia Oreochromis mossambicus (Peters 1852) juveniles. Aquatic Research, 2(4), 182-190. https://doi.org/10.3153/AR19017

Department of Aquatic Animal Health, Faculty of Fishery Sciences, West Bengal University of Animal and Fishery Sciences, Kolkata - 700 094, West Bengal, India

ORCID IDs of the author(s): T.J.A. 0000-0003-0581-1307 M.S.N. 0000-0002-6046-9703 H.A. $0000-0002-2258-1470$

S.B. 0000-0001-6527-4481

Submitted: 05.08.2019

Revision requested: 20.08 .2019

Last revision received: 18.09 .2019

Accepted: 20.09.2019

Published online: 25.09 .2019

Correspondence:

Thangapalam Jawahar ABRAHAM

E-mail: abrahamtj1@gmail.com

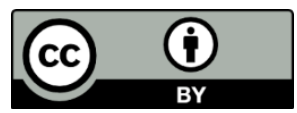

(C)Copyright 2019 by ScientificWebJournals Available online at

http://aquatres.scientificwebjournals.com

\begin{abstract}
Streptococcosis is one of the most important bacterial diseases of tilapia. The present study assessed the histopathological changes induced by Streptococcus agalactiae challenge in the brain, kidney, spleen, and liver of Oreochromis mossambicus. When challenged intraperitoneally at $10^{7}$ $10^{8}$ cells/fish, $S$. agalactiae strains ( $\mathrm{TKT}_{1}$ and $\mathrm{TBT}_{2}$ ) caused $40-100 \%$ mortalities in O. mossambicus. The $\mathrm{LD}_{50}$ values of $S$. agalactiae $\mathrm{TKT}_{1}$ and $\mathrm{TBT}_{2}$ strains were $1.60 \times 10^{7}$ and $7.33 \times 10^{7}$ cells/fish, respectively. Histological sections of the challenged $O$. mossambicus brain exhibited meningoencephalitis, marginated haemocytes, extensive haemorrhages, oedema and neurons with marginated nuclei. The kidney of challenged tilapia showed glomerulopathy, dilation of Bowman's capsule, nephritis, haematopoietic tissue necrosis, melanization and granulomatous-like lesions. The spleen was characterized by extensive melanomacrophage aggregation, necrosis and vasodilation. The liver had dilated and ruptured blood capillary, melanization and disintegrated tissue. The intrahepatic exocrine pancreatic tissue was disintegrated. Our results demonstrated that S. agalactiae caused a systemic infection and meningoencephalitis in the Mozambique tilapia juveniles.
\end{abstract}

Keywords: Oreochromis mossambicus, Streptococcus agalactiae, Meningoencephalitis, Pathogenicity, Granulomatous-like lesions 


\section{Introduction}

The Mozambique tilapia, Oreochromis mossambicus (Peters 1852 ) is endemic from the lakes and rivers of the East Coast of Africa (Trewavas, 1983). Tilapias have been purposely dispersed globally as baitfish, aquarium fish, food fish, and biological control agents. The culture of tilapias was also promoted to aid poor and rural families in developing tropical nations (Boyd, 2004). Tilapias are farmed commercially in over 140 countries with global culture production of about 6.5 million metric tonnes in 2017 and are second in sales and volume in international trade after salmonids and the second most farmed fish after carps globally. China is the largest producer of tilapia. The other major tilapia producers are Indonesia, Egypt, Thailand, Bangladesh, Brazil, and the Philippines (FAO, 2018). Oreochromis mossambicus is the second most important farmed tilapia species in the world, after the Nile tilapia, O. niloticus (El-Sayed, 2006). It was first introduced to India from Sri Lanka to boost fish production particularly in several reservoirs of India in 1952 (Sugunan, 1995). Now it forms a part of fish fauna in almost all the natural aquatic ecosystems of the Indian Territory. Tilapias are considered to be resistant to bacterial, parasitic, fungal, and viral diseases compared to other species of cultured fish (Galhardo, 2010). In recent times, tilapias in aquaculture conditions were reportedly susceptible to several bacterial and viral diseases (Eyngor et al., 2014; Zamri-Saad et al., 2014; FAO., 2017; Behera et al., 2018; Mishra et al., 2018). The common tilapia pathogens include Streptococcus spp., Flavobacterium columnare, Aeromonas hydrophila, Edwardsiella tarda, Ichthyophitirius multifiliis, Trichodina sp., and Gyrodactylus niloticus (El-Sayed, 2006; Klesius et al., 2008). Streptococcosis is one of the most significant diseases of tilapia and contributed to severe economic losses worldwide. An annual global loss of about US\$ 250 million has been attributed to streptococcosis (Amal and Zamri-Saad, 2011). Streptococcus iniae, S. agalactiae and other species of streptococci are the major bacterial species that affect the global tilapia production. Most outbreaks of streptococcosis in tilapia are caused by $S$. agalactiae that are influenced by the high water temperatures above $31^{\circ} \mathrm{C}$ (Evans et al., 2006; Amal and Zamri-Saad, 2011; Iregui et al., 2014). There are several reports and reviews of diseases of aquacultured tilapias (El-Sayed, 2006; Amal and Zamri-Saad, 2011; Iregui et al., 2014; Zamri-Saad et al., 2014; Mishra et al., 2018) and all pointed at streptococcosis as the major problem. Prevalence of streptococcal infection with meningoencephalitis in tilapia is rare in India until the observations in Nile tilapia, $O$. niloticus during the summer season (Adikesavalu et al., 2017). As tilapia aquaculture continues to expand as a means of food production in India, it becomes crucial to ensure that fish resources are protected from the adverse effects of diseases. An assessment of the severity of the disease in closely related species will provide a better understanding of mitigating the impacts of streptococcosis. This communication reports the pathogenicity and pathology of $S$. agalactiae in challenged $O$. mossambicus juveniles.

\section{Material and Methods}

\section{Bacterial Strains and Experimental Fish}

The non-haemolytic Streptococcus agalactiae strains $\left(\mathrm{TKT}_{1}\right.$ : NCBI accession number KP898209.1 and $\mathrm{TBT}_{2}$ : NCBI accession number KP898207.1) used in this study were from the collections of the Department of Aquatic Animal Health, West Bengal University of Animal and Fishery Sciences, Kolkata, India. The experimental fish O. mossambicus (Peters 1852) juveniles $(10.09 \pm 1.06 \mathrm{~cm} ; 23.58 \pm 4.96 \mathrm{~g})$ were procured from Naihati, West Bengal, India and brought to the laboratory in oxygen-filled polythene bags. On reaching the laboratory, they were disinfected by placing in 5 ppm potassium permanganate solution for $10 \mathrm{~min}$. The weakfish were removed immediately. The healthy ones were stocked at the rate of $100 \mathrm{fish} / \operatorname{tank}$ of $500 \mathrm{~L}$ capacity and acclimatized for 15 days with continuous aeration. The fish were fed a balanced dry pellet feed (CP Pvt. Ltd., India) twice daily at 3\% body weight (BW).

\section{Pathogenicity of Streptococcus agalactiae Strains $T_{K} T_{1}$ and $\mathrm{TBT}_{2}$}

Streptococcus agalactiae strains preserved as glycerol stock were revived in brain heart infusion broth (BHIB) at $30 \pm 1{ }^{\circ} \mathrm{C}$ for $24 \mathrm{~h}$ and maintained on $\mathrm{BHI}$ agar. One colony each was aseptically picked, transferred to $10 \mathrm{~mL}$ of BHIB separately and incubated at $30 \pm 1^{\circ} \mathrm{C}$ for $24 \mathrm{~h}$. The preparation of bacterial cell suspensions and the determination of numbers of cells in the saline suspensions are as described in Adikesavalu et al. (2015). The pathogenicity of $S$. agalactiae strains on $O$. mossambicus juveniles was tested by intraperitoneal injection in duplicate. Twenty thoroughly cleaned glass aquaria $(60 \times$ $45 \times 30 \mathrm{~cm}$ ) were filled with clean bore-well water to a volume of $30 \mathrm{~L}$ each and conditioned for three days. The healthy tilapia were stocked at the rate of 10 fish/aquaria and acclimatized for 3 days with continuous aeration. All fish were fed a balanced dry pellet feed twice daily at 3\% BW and maintained under optimal condition. The wastes and faecal matter were syphoned out and 50\% water exchange was done on alternate days. Before the challenge, the acclimatized fish were checked visually for the gross and external signs of diseases including the parasites on the body and gills. The bacterial 
infection in the tilapia kidney $(\mathrm{n}=2)$, if any, was tested on BHIA (Adikesavalu et al., 2017). The absence of gross and external signs of diseases and the bacterial growth on BHIA confirmed that the stocks were healthy and devoid of obvious diseases.

Twenty glass aquaria containing $O$. mossambicus were then divided into 10 groups. Oreochromis mossambicus from groups 1-4 received intraperitoneal injections containing 0.1 $\mathrm{mL}$ of $S$. agalactiae strain $\mathrm{TKT}_{1}$ at a dosage of $\geq 1.00 \times 10^{8}$, $1.00 \times 10^{7}, 1.00 \times 10^{6}$ and $1.00 \times 10^{5}$ cells/fish, respectively. Similarly, the tilapia of groups 5-8 received intraperitoneal injections containing $0.1 \mathrm{~mL}$ of $S$. agalactiae strain $\mathrm{TBT}_{2}$ at similar doses as above. The fish of group 9 were injected with $0.1 \mathrm{~mL}$ of sterile physiological saline. Group 10 received no injection and served as negative control. The challenged and control groups were maintained in the respective aquaria for 28 days. The external signs of infection, behavioural abnormalities and mortality were recorded daily. The bacterium $S$. agalactiae was reisolated from freshly dead fish on BHIA and confirmed phenotypically. The lethal dose at which 50\% of the experimental populations die $\left(\mathrm{LD}_{50}\right)$ was calculated as per Reed and Muench (1938).

\section{Histopathology}

The organs such as brain, kidney, liver, and spleen of the challenged $O$. mossambicus were fixed in Bouin's solution for $24 \mathrm{~h}$. The fixed organs were processed by standard techniques and embedded in paraffin wax. Thin $(5 \mu \mathrm{m})$ sections were prepared and stained with haematoxylin and eosin for the detection of histopathological changes (Roberts, 2012).

\section{Results and Discussion}

Streptococcus agalactiae has been isolated from numerous fish species in natural outbreaks of disease and is pathogenic to several fish species in experimental trials using different routes of infection such as cohabitation, immersion, intraperitoneal and intramuscular injections (Evans et al., 2002). A perusal of literature revealed $O$. mossambicus is an invasive species and relatively resistant to diseases; while its hybrid red tilapia (Oreochromis mossambicus $\times$ Oreochromis nilot$i c u s$ ) and $O$. niloticus are highly sensitive to streptococcal infection (Hernández et al., 2009; Amal and Zamri-Saad, 2011). In challenged $O$. mossambicus of this study, gross and clinical signs started to appear within $24 \mathrm{~h}$ of injection and these include lethargy, poor escape response, erratic movement, excess mucous secretion on the gills, petechial haemorrhages on the inner and outer opercula, and focal cutaneous haemorrhages on the belly, lower jaw and at the base of the paired fins. The main internal signs were abdominal ascites, haemorrhages in the kidney, discolouration of internal organs and hyperemia of meninges. Before dying, some fish showed spinning and erratic patterns of swimming. These gross and clinical signs corroborate the observations of earlier studies (El-Sayed, 2006; Iregui et al., 2014; Zamri-Saad et al., 2014). In an earlier study, Tung (1985) reported natural streptococcal infection in cultured $O$. mossambicus, but not explicitly due to $S$. agalactiae infection. Hernández et al. (2009) demonstrated the infection and disease by $S$. agalactiae in cultivated red tilapia, but not in eighteen wild fish species inhabiting the same aquatic environment that also included $O$. mossambicus. The intraperitoneal challenge with $S$. agalactiae $\mathrm{TKT}_{1}$ and $\mathrm{TBT}_{2}$ at $10^{8}$ cells/fish caused $100 \%$ and $90 \%$ mortalities within 72 hours of challenge, respectively. While at a challenge dose of $10^{7}$ cells/fish, these strains caused $70 \%$ and $40 \%$ mortalities in 7 days, respectively. No or negligible mortalities were noted at the lower challenge doses. The $\mathrm{LD}_{50}$ values of $\mathrm{TKT}_{1}$ and $\mathrm{TBT}_{2}$ strains were $1.60 \times 10^{7}$ and $7.33 \times 10^{7}$ cells/fish, respectively. Oreochromis mossambicus is not prone to diseases, having high resistance to most viral, bacterial and parasitic infections (Hernández et al., 2009; Galhardo, 2010). In few studies, O. mossambicus have been used as experimental models to initiate streptococcosis (Ndong et al., 2007; Yilmaz et al., 2013; Gültepe et al., 2014) as was in this study. The intraperitoneal challenge experiments and the $\mathrm{LD}_{50}$ results of $1.60 \times 10^{7}$ and $7.33 \times 10^{7}$ cells/fish, respectively for $S$. agalactiae $\mathrm{TKT}_{1}$ and $\mathrm{TBT}_{2}$ strains suggested the moderately virulent potential of these strains in O. mossambicus. In contrast, Mukhi (1999) observed $100 \%$ mortality in O. mossambicus within $48 \mathrm{~h}$ of intraperitoneal injection with Streptococcus spp. at $10^{7}-10^{9}$ cells $/ \mathrm{mL}$ levels. On the other hand, the $\mathrm{LD}_{50}$ values of $5.30 \times 10^{6}-6.80 \times 10^{6}$ cells/fish (Wang et al., 2013) and $5.27 \times 10^{7}$ cells/fish (Li et al., 2014) for $S$. agalactiae strains in $O$. niloticus have been documented. Though the $S$. agalactiae strains of the present study were only moderately virulent, they can be considered as true pathogens by their ability to cause meningoencephalitis in challenged $O$. mossambicus. Notably, S. agalactiae has not been isolated earlier in O. mossambicus and other wild species inhabiting the same aquatic environment that cohabit diseased red tilapia (Hernández et al., 2009). But in challenge experiments with O. mossambicus, a closely related species $S$. iniae was able to elicit mortalities (Ndong et al., 2007; Yilmaz et al., 2013; Gültepe et al., 2014). The observed high $\mathrm{LD}_{50}$ values suggested that the solitary presence of $S$. agalactiae in the aquatic environment is not enough to induce the disease. The concomitant factors or risk factors, viz., high temperatures $\left(>31^{\circ} \mathrm{C}\right)$ or strong temperature fluctuations, poor water quality, crowding, etc may severely affect the physiology of tilapia and increase their susceptibility to the agent, which predispose $S$. agalactiae 
outbreaks in tilapia (Evans et al., 2006; Amal and ZamriSaad, 2011; Iregui et al., 2014).

Several earlier reports revealed that $S$. agalactiae caused systemic infection in tilapia (Al-Harbi, 1996; Amal and ZamriSaad, 2011; Zamri-Saad et al., 2010; 2014; Iregui et al., 2016; Mishra et al., 2018). The common histopathological lesions of $S$. agalactiae infection consisted of focal to multifocal, mild to severe granulomatous inflammation and multifocal, acute, necrotic inflammatory lesions. Also, S. agalactiae has a predilection for the brain as it is the primary organ for infection (Hernández et al., 2009; Iregui et al., 2014; Iregui et al., 2016). The histological sections of experimentally in- fected $O$. mossambicus brain revealed extensive haemorrhages, lymphocyte infiltration in the meninges, increase in intercellular space possibly due to oedema, neurons with marginated nuclei and marginated haemocytes (Figure 1a-d), all of which are indicators of $S$. agalactiae infection (ZamriSaad et al., 2010; Alsaid et al., 2013; Adikesavalu et al., 2017). The observations on the extensive haemorrhages and haemocyte infiltration in the meninges suggested meningoencephalitis. Conspicuously, S. agalactiae strains, isolated from O. niloticus with severe meningoencephalitis (Adikesavalu et al., 2017), were able to elicit similar disease manifestations in a relatively hardy species like $O$. mossambicus.
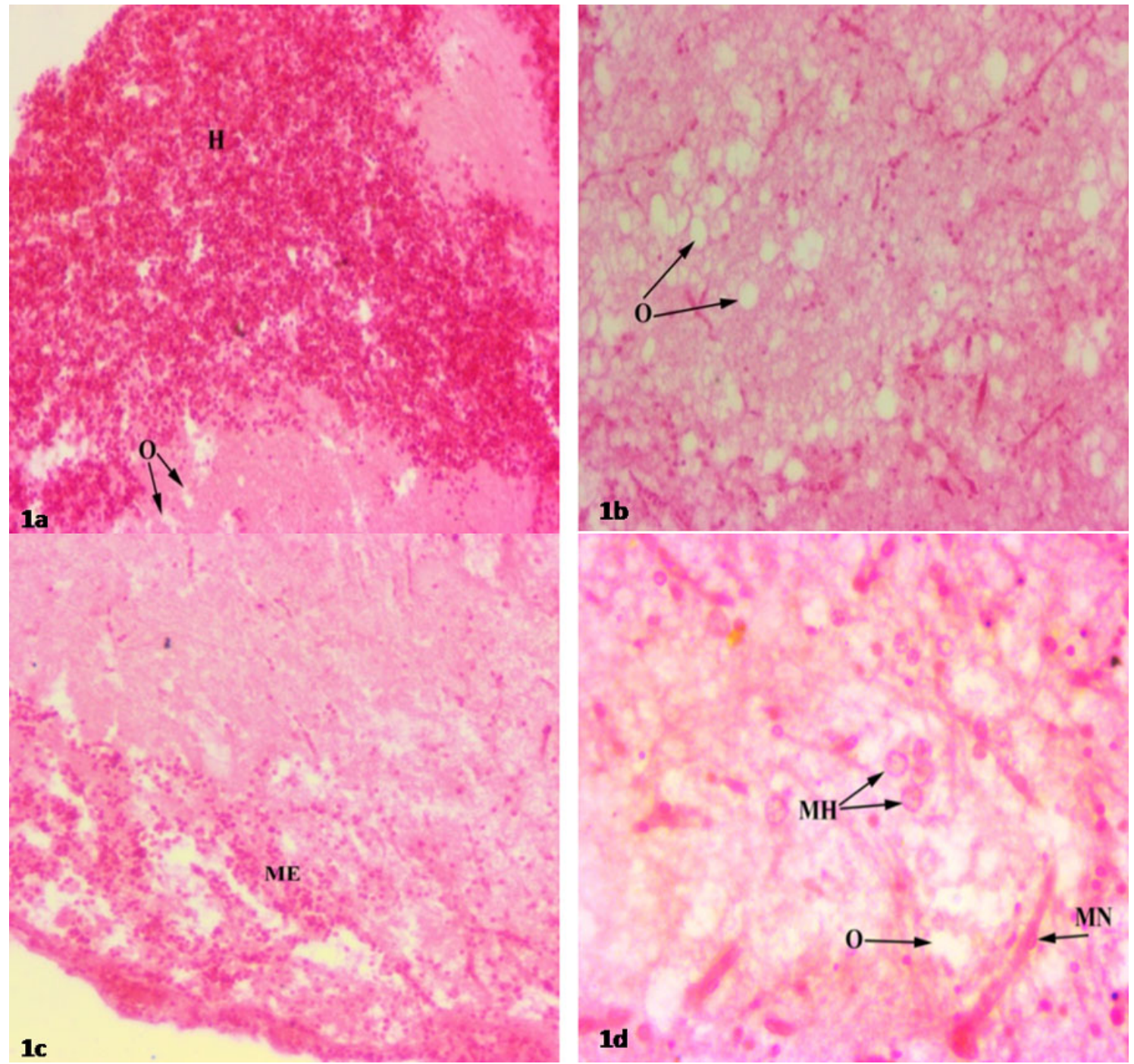

Figure 1. Histopathological changes in the brain tissues of Oreochromis mossambicus intraperitoneally infected with Streptococcus agalactiae showing (a) extensive haemorrhages $(\mathrm{H})$ and oedema $(\mathrm{O}), \mathrm{X100}$; (b) extensive increase in intercellular space indicating oedema (O), X200; (c) macrophage and lymphocyte infiltration in meninges indicating meningoencephalitis (ME), X200 and (d) neurons with marginated nucleus (MN), marginated haemocytes (MH) and oedema (O), X400 H \& E 


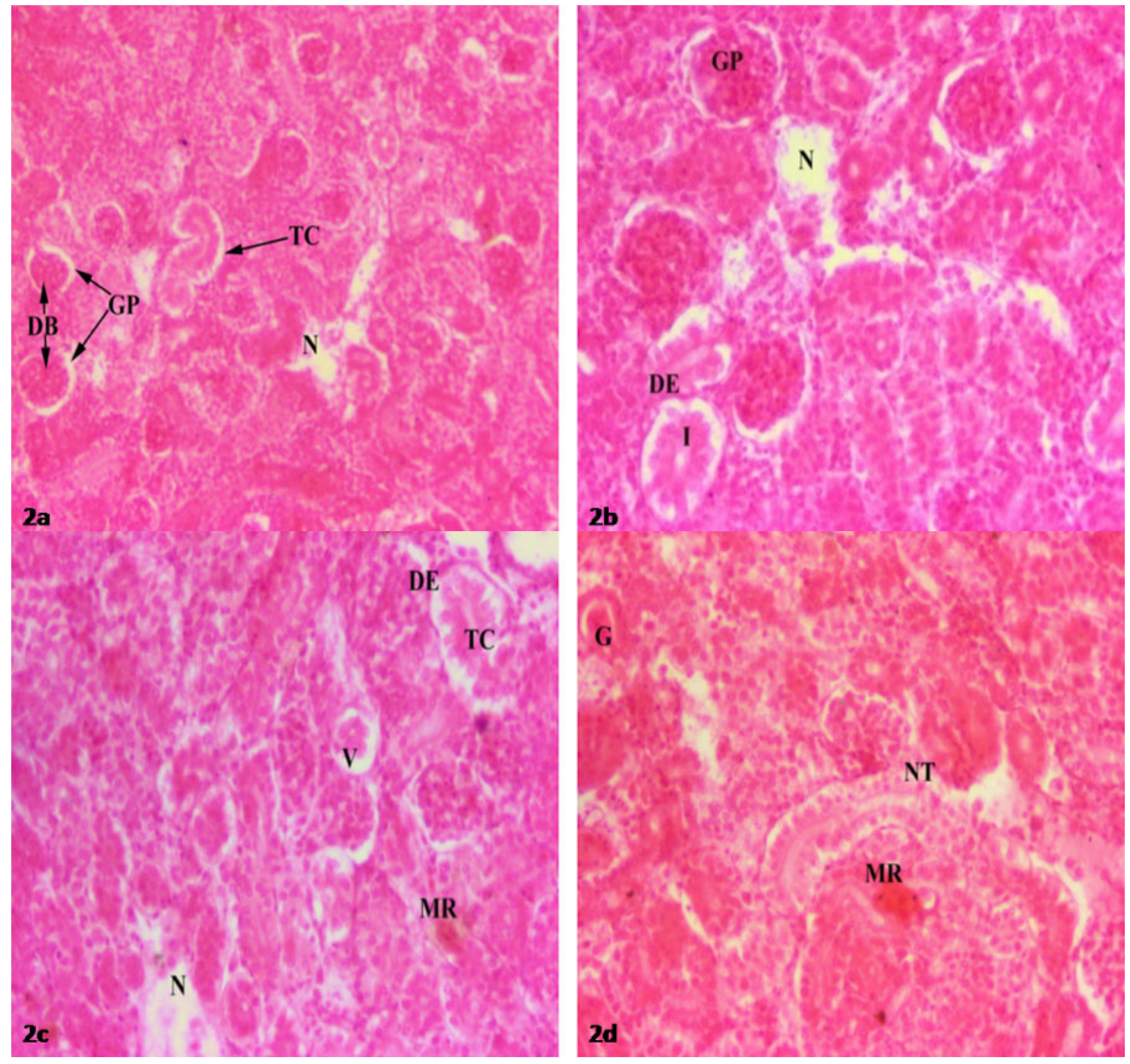

Figure 2. Histopathological changes in the kidney tissues of Oreochromis mossambicus intraperitoneally infected with Streptococcus agalactiae showing (a) necrosis (N), constricted tubular lumen (TC), glomerulopathy (GP) with dilated Bowman's capsule (DB), X100; (b) glomerulopathy (GP), necrotised area (N), inflamed nephritic tubule (I) with degraded epithelium layer (DE), X200; (c) highly necrotised haematopoietic tissue (N), constricted tubular lumen (TC) with degraded tubule epithelium (DE), melanin reaction (MR) and vacuolation (V), X200; and (d) melanin reaction (MR), necrotised tubular lumen (NT) and granulomatous-like lesion (G), X200 H \& E

The histological sections of the kidney, spleen and liver of $O$. mossambicus also demonstrated a variety of pathological alterations. The kidney tissues of $O$. mossambicus exhibited necrosis, necrotised and constricted tubular lumen, glomerulopathy with dilated Bowman's capsule, inflamed nephritic tubule, degraded epithelial layer, highly necrotised haematopoietic tissue, melanin reaction, vacuolation and granulomatous-like lesion (Figure 2a-d). The spleen tissues showed basophilic bodies, depletion of splenocytes and liquefactive necrosis foci, extensive melanomacrophage aggregation (Fig- ure 3a-b). Alterations such as dilated and ruptured blood capillary, disintegration of the liver as well as intrahepatic exocrine pancreatic tissues and melanin reaction were noted in the liver (Figure 4a-b). The observations on the presence of granulomatous-like lesions as a primary inflammatory response in the kidney corroborate the earlier reports (Pulido et al., 2004; Li et al., 2014; Adikesavalu et al., 2017). The formation of melanomacrophage aggregation was, rather, extensive in the spleen compared to the kidney and liver. These observations suggested that intense immune responses 
against the invading $S$. agalactiae occurred in this major lymphoid organ of tilapia. Our challenge results thus, suggested that $S$. agalactiae can cause similar pathology in $O$. mossambicus as has been observed in S. agalactiae infected $O$. niloticus (Li et al., 2014; Adikesavalu et al., 2017), red tilapia, Oreochromis spp. (Zamri-Saad et al., 2010) and red hybrid

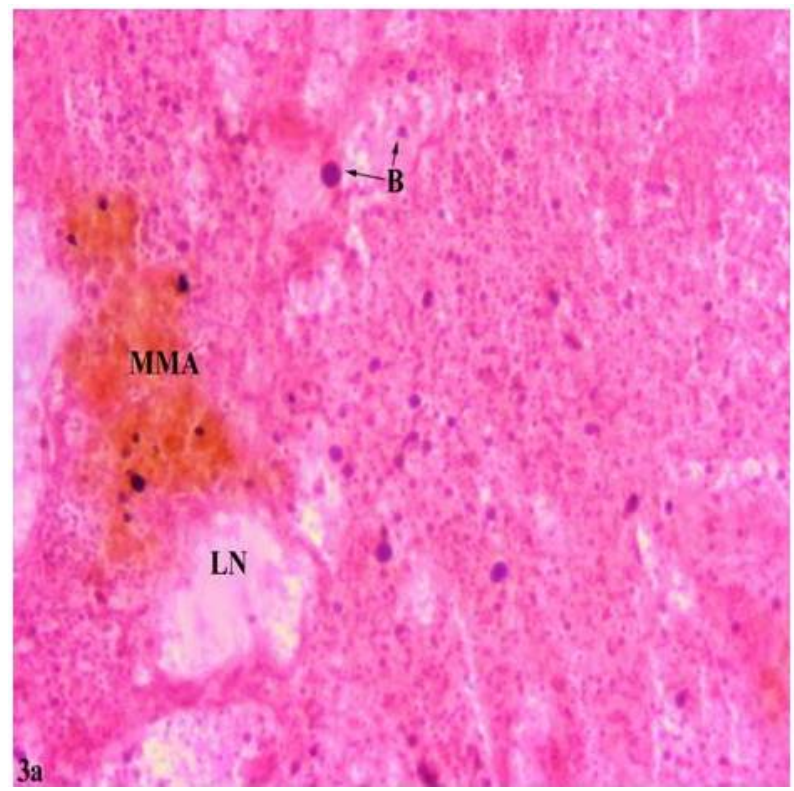

tilapia, Oreochromis sp. (Alsaid et al., 2013). Further, S. agalactiae isolated from diseased $O$. niloticus could be experimentally transmitted to $O$. mossambicus, thereby suggesting a possibility of horizontal transmission (e.g. fish to fish) among cultured species in the same ecosystem as was demonstrated earlier in cultured marine fish from the wild population (Zlotkin et al., 1998).

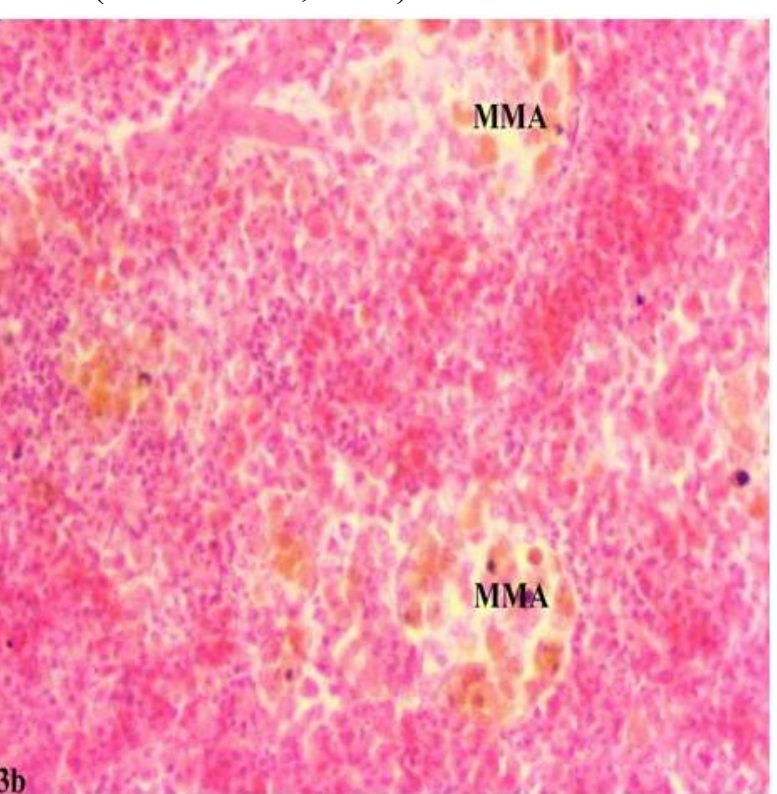

Figure 3. Histopathological changes in the spleen tissues of Oreochromis mossambicus intraperitoneally infected with Streptococcus agalactiae showing (a) basophilic bodies (B), melanomacrophage aggregation (MMA), depletion of splenocytes and liquefactive necrosis foci (LN) X200 and (b) melanomacrophage aggregation (MMA), X200 H \& E
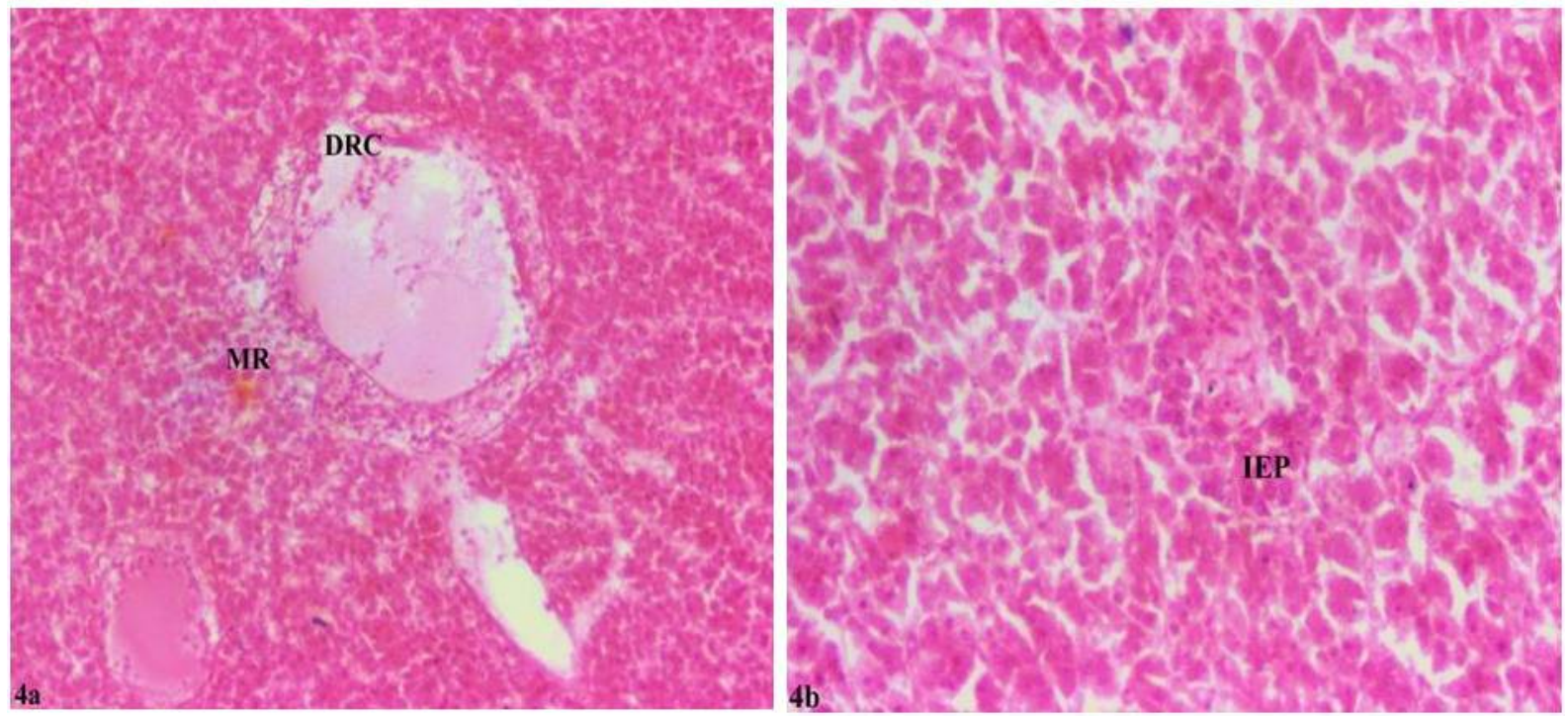

Figure 4. Histopathological changes in the liver tissues of Oreochromis mossambicus intraperitoneally infected with Streptococcus agalactiae showing (a) melanin reaction (MR), dilated and ruptured blood capillary (DRC), X200 and (b) disintegration of intrahepatic exocrine pancreatic tissue (IEP), X200 H \& E 


\section{Conclusion}

It is well established that $S$. agalactiae has low-host specificity. The sign of meningoencephalitis in $S$. agalactiae challenged $O$. mossambicus suggested that cross-infection may occur between the wild and cultured fish, which share the same environment. Nevertheless, the possible transmission by horizontal route in Nile tilapia is of only limited significance in well-managed culture systems.

\section{Compliance with Ethical Standard}

Conflict of interests: The authors declare that for this article they have no actual, potential or perceived conflict of interests.

Ethics committee approval: Experimental design and fish handling of the current study had been approved by the Research Ethical Committee of West Bengal University of Animal and Fishery Sciences, Kolkata, India.

Financial disclosure: The research work was supported by the Indian Council of Agricultural Research, Government of India, New Delhi under the Niche Area of Excellence programme vide Grant F. 10(12)/2012-EPD dated 23.03.2012.

Acknowledgments: The authors thank the Vice-Chancellor, West Bengal University of Animal and Fishery Sciences, Kolkata, India for providing necessary infrastructure facility to carry out the work.

\section{References}

Adikesavalu, H., Patra, A., Banerjee, S., Sarkar, A., Abraham, T.J. (2015). Phenotypic and molecular characterization and pathology of Flectobacillus roseus causing flectobacillosis in captive held carp Labeo rohita (Ham.) fingerlings. Aquaculture, 439, 60-65.

https://doi.org/10.1016/j.aquaculture.2014.12.036

Adikesavalu, H., Banerjee, S., Patra, A., Abraham, T.J. (2017). Meningoencephalitis in farmed mono-sex Nile tilapia (Oreochromis niloticus L.) caused by Streptococcus agalactiae. Archives of Polish Fisheries, 25, 187-200.

https://doi.org/10.1515/aopf-2017-0018

Al-Harbi A.H. (1996). Susceptibility of five species of tilapia to Streptococcus sp. Asian Fisheries Science, 9, 177181.

Alsaid, M., Daud, H.H.M., Mustapha, N.M., Bejo, S.K., Abdelhadi, Y.M., Abuseliane, A.F., Hamdan, R.H.
(2013). Pathological findings of experimental Streptococcus agalactiae infection in red hybrid tilapia (Oreochromis sp.). In Proceedings of the International Conference on Chemical, Agricultural and Medical Sciences (CAMS-2013), (p. 7073). Kuala Lumpur, Malaysia.

Amal, M.N.A., Zamri-Saad, M. (2011). Streptococcosis in tilapia (Oreochromis niloticus): a review. Pertanika Journal of Tropical Agricultural Science, 34, 195-206.

Behera, B.K. Pradhan, P.K., Swaminathan, T.R., Sood, N., Prasenjit, P., Das, A., Verma, D.K., Kumar, R., Yadav M.K., Dev, A.K., Parida, P.K., Das, B.K., Lal, K.K., Jena, J.K. (2018). Emergence of Tilapia Lake Virus associated with mortalities of farmed Nile Tilapia Oreochromis niloticus (Linnaeus 1758) in India. Aquaculture, 484, 168-174. https://doi.org/10.1016/j.aquaculture.2017.11.025

Boyd, C.E. (2004). Farm-level Issues in Aquaculture Certification: Tilapia. Report commissioned by WWF, p.29. Available at http://fisheries.tamu.edu/files/2013/09FarmLevel-Issues-in-Aquaculture-Certification-Tilapia.pdf (accessed on 19 October 2017)

El-Sayed, A.F.M. (2006). Tilapia culture. Wallingford: CAB International, p.277.

https://doi.org/10.1079/9780851990149.0000

Evans, J.J., Klesius, P.H., Gilbert, P.M., Shoemaker, C.A., Al-Sarawi, M.A., Landsberg, J., Duremdez, R., AlMarzouk, A., Al-Zenki, S. (2002). Characterization of betahemolytic Group B Streptococcus agalactiae in cultured gilthead seabream, Sparus auratus (L.) and wild mullet, Liza klunzingeri (Day), in Kuwait. Journal of Fish Diseases, 5, 505-513.

https://doi.org/10.1046/j.1365-2761.2002.00392.x

Evans, J.J., Klesius, P.H., Shoemaker, C.A. (2006). An overview of streptococcus in warm-water fish. Aquaculture Health International, 7, 10-14.

Eyngor, M., Zamostiano, R., Tsofack, J.E.K., Berkowitz, A., Bercovier, H., Tinman, S., Lev, M., Hurvitz, A., Galeotti, M., Bacharach, E., Eldara, A. (2014). Identification of 
a novel RNA virus lethal to tilapia. Journal of Clinical Microbiology, 52(12), 4137-4146.

https://doi.org/10.1128/JCM.00827-14

FAO (2017). Outbreaks of Tilapia lake virus (TiLV) threaten the livelihoods and food security of millions of people dependent on tilapia farming. GIEWS Special Alert No: 338 - Global. Available at: http://www.fao.org/3/a-i7326e.pdf (accessed on 20 October 2017).

FAO (2018). The State of World Fisheries and Aquaculture 2018 - Meeting the sustainable development goals. Rome. Licence: CC BY-NC-SA 3.0 IGO.

Galhardo, L. (2010). Teleost welfare: Behavioural, cognitive and physiological aspects in Oreochromis mossambicus. $\mathrm{PhD}$ thesis. Porto, Portugal: Instituto De Ciências Biomédicas Abel Salazar, Universidade Do Porto, p.215

Gültepe, N., Bilen, S., Yilmaz, S., Güroy, D., Aydin, S. (2014). Effects of herbs and spice on health status of tilapia (Oreochromis mossambicus) challenged with Streptococcus iniae. Acta Veterinaria Brno, 83, 125-131.

https://doi.org/10.2754/avb201483020125

Hernández, E., Figueroa, J., Iregui, C. (2009). Streptococcosis on a red tilapia, Oreochromis sp., farm: a case study. Journal of Fish Diseases, 32, 247-252.

https://doi.org/10.1111/j.1365-2761.2008.00981.x

Iregui, C., Barato, P., Rey, A., Vasquez, G., Verján, N. (2014). Epidemiology of Streptococcus agalactiae and Streptococcosis in tilapia fish. In iConcept Press Ltd (ed.), Epidemiology: Theory, Research and Practice. 1st edn. Chapter 10. Hong Kong: iConcept Press Ltd, pp.18.

Iregui, C., Comas, J., Vásquez, G.M., Verján, N. (2016). Experimental early pathogenesis of Streptococcus agalactiae infection in red tilapia Oreochromis spp. Journal of Fish Diseases, 39, 205-215.

https://doi.org/10.1111/jfd.12347

Klesius, P.H., Shoemaker, C.A., Evans, J.J. (2008). Streptococcus: A worldwide fish health problem. In Proceedings of the 8th International Symposium on Tilapia in Aquaculture. (p. 83-107). Cairo, Egypt.
Li, Y.W., Liu, L., Huang, P.R., Fang, W., Luo, Z.P., Peng, H.L., Wang, X.Y., Li, A.X. (2014). Chronic streptococcosis in Nile tilapia, Oreochromis niloticus (L.) caused by Streptococcus agalactiae. Journal of Fish Diseases, 37, 757-763. https://doi.org/10.1111/jfd.12146

Mishra, A., Nam, G-H., Gim, J-A., Lee, H-E., Jo, A., Kim, H-S. (2018). Current challenges of streptococcus infection and effective molecular, cellular, and environmental control methods in aquaculture. Molecules and Cells, 41(6), 495505.

Mukhi, S.K. (1999). Streptococcal Infection in Cultured Tilapia Oreochromis mossambicus (Peters). Master's thesis. Mumbai, India: Central Institute of Fisheries Education, p.66.

Ndong, D., Chen, Y.Y., Lin, Y.H., Vaseeharan, B., Chen, J.C. (2007). The immune response of tilapia Oreochromis mossambicus and its susceptibility to Streptococcus iniae under stress in low and high temperatures. Fish and Shellfish Immunology, 22(6), 686-694.

https://doi.org/10.1016/j.fsi.2006.08.015

Pulido, E., Iregui, C., Figueroa, J., Klesius, P.H. (2004). Estreptococosis en tilapias (Oreochromis spp.) cultivadas en Colombia. Revista Aquatic, 20, 97-106.

Reed, L.J., Muench, H. (1938). A simple method of estimating fifty percent endpoints. American Journal of Epidemiology, 27(3), 493-497.

https://doi.org/10.1093/oxfordjournals.aje.a118408

Roberts, R.J. (2012). Fish Pathology (4th ed.). WileyBlackwell, UK. p. 590.

https://doi.org/10.1002/9781118222942

Sugunan, V.V. (1995). Exotic Fishes and their Role in Reservoir Fisheries in India. FAO Fisheries Technical Paper No. 345. Rome: FAO, p.423.

Trewavas, E. (1983). Tilapine fishes of the genera Sarotherodon, Oreochromis and Danakilia, London, UK: British Museum (Natural History) https://doi.org/10.5962/bhl.title. 123198 
Tung, M.C., Chen, S.C., Tsai, S.S. (1985). General septicemia of streptococcal infection in cage-cultured Tilapia mossambica in southern Taiwan. COA Fisheries Series No. 4, Fish Disease Research, VII: 95-105.

Wang, K.Y., Chen, D.F., Huang, L.Y., Lian, H., Wang, J., Xiao, D., Geng, Y., Yang, Z.X., Lai, W.M. (2013). Isolation and characterization of Streptococcus agalactiae from Nile tilapia Oreochromis niloticus in China. African Journal of Microbiology Research, 7, 317-323.

https://doi.org/10.5897/AJMR12.1207

Yilmaz, S., Ergün, S., Soytaş, N. (2013). Herbal supplements are useful for preventing streptococcal disease during first-feeding of tilapia fry, Oreochromis mossambicus. Israeli Journal of Aquaculture Bamidgeh, 65, 833.
Zamri-Saad, M., Amal, M.N.A., Siti-Zahrah, A. (2010). Pathological changes in red tilapias (Oreochromis spp.) naturally infected by Streptococcus agalactiae. Journal of Comparative Pathology, 143, 227-229.

https://doi.org/10.1016/j.jcpa.2010.01.020

Zamri-Saad, M., Amal, M.N.A., Siti-Zahrah, A., Zulkafli, A.R. (2014). Control and prevention of streptococcosis in cultured tilapia in Malaysia: A review. Pertanika Journal of Tropical Agricultural Science, 37(4), 389-410.

Zlotkin, A., Hershko, H., Eldar, A. (1998). Possible transmission of Streptococcus iniae from wild fish to cultured marine fish. Applied and Environmental Microbiology, 64, 4065-4067. 